\title{
Microinjection of LHRH and Its Antagonistic Analog into the Medial Preoptic Area Does Not Affect Pulsatile Secretion of LH in Ovariectomized Rats
}

\author{
TOSHIYA FUNABASHI, RyuUhei HASHIMOTO, \\ KaYOKo JINNAI AND FuKuKo KIMURA \\ Department of Physiology, Yokohama City University \\ School of Medicine, Yokohama 236, Japan
}

\begin{abstract}
To gain a better understanding of the existence of an ultra-short feedback mechanism controlling LHRH secretion in the medial preoptic area (MPO), we examined the effects of microinjections of LHRH or the LHRH antagonist [D-pGlu ${ }^{1}, \mathrm{D}-\mathrm{Phe}^{2}, \mathrm{D}-\mathrm{Try}^{3,6}$ ] into the MPO on pulsatile secretion of LH in ovariectomized rats and on the surge of $\mathrm{LH}$ secretion in proestrous rats. Neither the injection of $10 \mathrm{ng}$ LHRH nor $100 \mathrm{ng}$ its antagonist into the MPO had any effect on pulse frequency or the mean LH concentration in ovariectomized rats. The injection of $100 \mathrm{ng}$ LHRH antagonist or $10 \mathrm{ng}$ LHRH delayed or advanced, respectively, the LH surge in proestrous rats. Taking these results together with our previous report, the present study indicates that 1) endogenous LHRH in the MPO is involved in the ultra-short feedback regulation of LHRH release and 2) the ultra-short positive feedback mechanism in the MPO acts at the time of the proestrous LH surge but not under a hormonal milieu as in ovariectomized rats.
\end{abstract}

Key words: LHRH, Preoptic area, Feedback, LH, Ovariectomy, LHRH antagonist

(Endocrine Journal 41: 559-563, 1994)

IT HAS BEEN reported that intraventricular injection of LHRH or LHRH agonist reduces the secretion of LHRH [1] and thus the secretion of LH is decreased in ovariectomized (OVX) rats $[2,3]$ and ewes [4], implying the existence of an ultra-short negative feedback mechanism for the control of LHRH secretion. In addition, in vitro studies have suggested that the neural structure that is involved in the mechanism is in the mediobasal hypothalamus including the median eminence $[5,6]$.

On the other hand, we have shown [7] that LHRH injected into the medial preoptic area (MPO) potentiates the surge of LH secretion in OVX estrogen-primed and proestrous rats, suggesting the existence of an ultra-short positive

Received: March 8, 1994

Accepted: June 30, 1994

Correspondence to: Dr. Toshiya FUNABASHI, Department of Physiology, Yokohama City University School of Medicine, 3-9 Fukuura, Kanazawa-ku, Yokohama 236, Japan feedback mechanism in the MPO, instead of a negative one as reported by others. The discrepancies between our results and those of others might be due to differences of the influence of gonadal steroids or the site of injection. We therefore examined the effect of the microinjection of LHRH or LHRH antagonist into the MPO on the pulsatile $\mathrm{LH}$ secretion in OVX rats. We also examined the effect of LHRH antagonist and LHRH on the LH surge in proestrous rats and compared it with the effect in OVX rats.

\section{Materials and Methods}

Female Wistar-Imamichi rats were obtained from the Animal Reproduction Research (Omiya, Japan) at 7-8 weeks of age and were maintained under controlled lighting conditions (lights on $0700 \mathrm{~h}-1900 \mathrm{~h}$ ), with food and water available ad 
libitum. Daily vaginal smears were obtained after the implantation of a guide cannula, and animals exhibiting 2 or more consecutive 4-day estrous cycles were used on the day of proestrus. Some of the animals were OVX 2 weeks prior to the implantation of the guide cannula into the brain.

The guide cannula was stereotaxically implanted into the MPO as reported previously [7]. Ten ng of LHRH (Peptide Institute, Minoo, Japan) or $100 \mathrm{ng}$ of its antagonistic analog [D-pGlu ${ }^{1}$, D-Phe ${ }^{2}$, D-Try ${ }^{3,6}$ ] LHRH (Peninsula Laboratories, INC., Belmont, USA) [8] was dissolved in $2 \mu l$ sterile saline and injected unilaterally into the MPO in OVX rats. Control rats were treated unilaterally with the same volume of saline. In proestrous rats, the LHRH antagonist (50 $\mathrm{ng} / 2 \mu \mathrm{l} / \mathrm{side}$ ) was injected bilaterally into each side of the MPO to sufficiently inhibit the action of a large amount of LHRH secreted on the day of proestrus $[9,10]$. Control rats were treated bilaterally with the same volume of saline. In the other experiment, $10 \mathrm{ng}$ of LHRH dissolved in $2 \mu l$ sterile saline was injected unilaterally into the MPO in proestrous rats. Control rats were treated unilaterally with the same volume of saline. Microinjections were performed immediately after the end of the first 90-min control sampling in OVX rats and at $1300 \mathrm{~h}$ after control sampling in proestrous rats. The other procedures are the same as reported previously [7] including the analysis of LH pulsatility [11, 12].

Serum concentrations of LH were measured by double-antibody radioimmunoassay with materials supplied by the National Institute of Diabetes and Digestive and Kidney Diseases (NIDDK). The reference standard used was NIDDK rat LH-RP-3, but the amount of $\mathrm{LH}$ is expressed in terms of NIH LH-S1. The hormone assay was done for each of the experiment, and thus a total 3 assays were run. The mean minimally detectable amount of $\mathrm{LH}$ (95\% confidence limits of buffer controls) for the 3 assays was $0.22 \pm 1.1$ (mean $\pm \mathrm{SD}$ ) $\mathrm{ng} / \mathrm{ml}$. The intra- and inter-assay coefficients of variation at mean $\mathrm{LH}$ values of $16.3 \pm 1.1$ (mean $\pm \mathrm{SEM}$ ) $\mathrm{ng} / \mathrm{ml}$ were $3.7-9.5 \%$ and $15.9 \%$, respectively.

Statistical comparison of the 90 -min pretreatment period with the 90-min post-treatment period was done by Wilcoxon matched-pairs signed-rank test. In the experiment for proestrous rats, analysis of variance was used to test the statistical significance of fluctuations over time in the mean hormone values for each sampling time. MannWhitney $U$ test was used to test the significance of difference between treatment groups. After the experiments were finished, locations of the guide cannulae were microscopically identified in frozen sections of the brain. Data for the animals with the cannula located outside the MPO were discarded. The site of the implanted cannula is shown in Fig. 1.

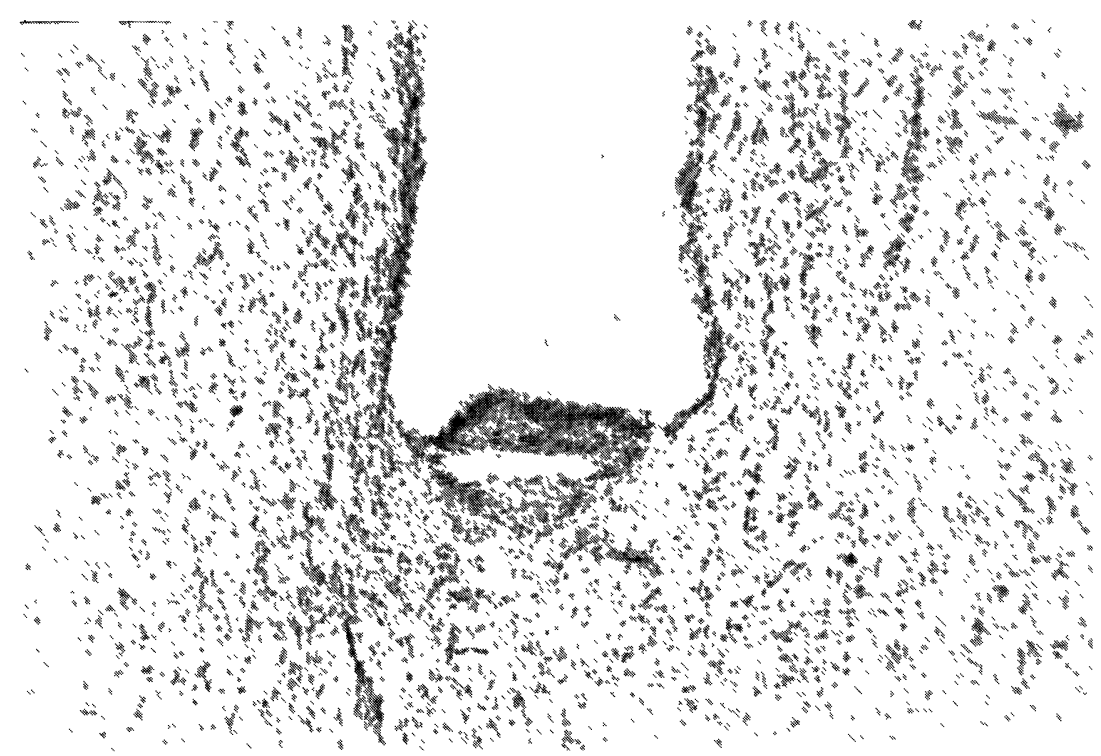

Fig. 1. Photograph of the tip of the cannula implanted in the MPO. The rats were perfused with $10 \%$ formalin, and $50 \mu \mathrm{m}$ frozen sections were made. The sections were stained with cresyl violet. No remarkable damage or change around the tip of cannula was observed. 


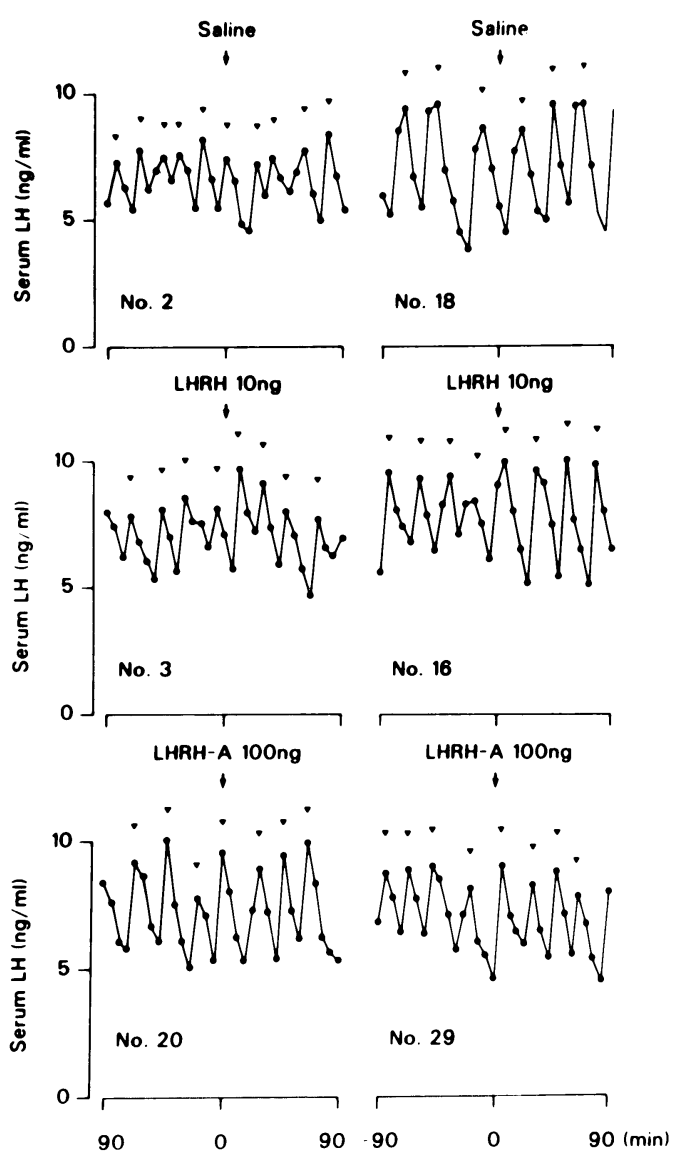

Fig. 2. Representative profiles of the serum LH concentration in the ovariectomized rats that received saline (upper), $10 \mathrm{ng}$ LHRH (middle) or $100 \mathrm{ng}$ LHRH antagonist (LHRH-A; lower) injections into the MPO. Arrows indicate the time of injection and arrowheads statistically define pulses.

\section{Results}

Representative profiles of serum LH in OVX rats that received injections of saline, LHRH or LHRH antagonist into the MPO are shown in Fig. 2. Regardless of the treatment, each rat exhibited clear pulsatile secretion of $\mathrm{LH}$ as usually observed in OVX rats. Injections of neither $10 \mathrm{ng}$ LHRH nor $100 \mathrm{ng}$ LHRH antagonist caused significant changes in the overall mean LH or the pulse frequency in OVX rats (Table 1). In contrast, in proestrous rats, the microinjection of $100 \mathrm{ng} \mathrm{LHRH}$ antagonist into the MPO caused a significant decrease in the $\mathrm{LH}$ concentration at $1500 \mathrm{~h}$ and an increase at 1800, 1900 and $2000 \mathrm{~h}$ compared with that in saline-treated proestrous rats (Table 2). LHRH antagonist injection therefore resulted in a delay of approximately $1 \mathrm{~h}$ in the peak time of the LH surge. In addition, unilateral microinjection of $10 \mathrm{ng}$ LHRH into the MPO in proestrous rats, which was not effective in OVX rats, significantly increased the LH concentration at $1500 \mathrm{~h}$ and 1600 $\mathrm{h}$, and decreased it at $1900 \mathrm{~h}$ and $2000 \mathrm{~h}$ compared with that in saline-treated control rats (Table 3 ). As a result, LHRH injection advanced the $\mathrm{LH}$ surge by approximately $1 \mathrm{~h}$.

\section{Discussion}

In the present study, the microinjection of LHRH and LHRH antagonist did not affect any parameter

Table 1. Effects of saline, LHRH and LHRH antagonist (LHRH-A) injection into the MPO on the LH pulse parameters

\begin{tabular}{lcccccc}
\hline \multirow{2}{*}{ Treatment } & \multirow{2}{*}{ Number of rats } & \multicolumn{2}{c}{ Mean LH $(\mathrm{ng} / \mathrm{ml})$} & & \multicolumn{2}{c}{ Pulse frequency (number/90 min) } \\
\cline { 6 - 6 } & & Before $90 \mathrm{~min}$ & After 90 min & & Before 90 min & After 90 min \\
\hline Saline & 8 & $6.5 \pm 0.1$ & $6.3 \pm 0.2$ & & $4.1 \pm 0.5$ & $3.4 \pm 0.4$ \\
LHRH 10 ng & 6 & $6.9 \pm 0.1$ & $6.7 \pm 0.2$ & & $3.8 \pm 0.3$ & $3.4 \pm 0.2$ \\
LHRH-A 100 ng & 9 & $6.9 \pm 0.1$ & $6.7 \pm 0.1$ & & $4.0 \pm 0.0$ & $3.7 \pm 0.4$ \\
\hline
\end{tabular}

Values are expressed as the mean \pm SEM.

Table 2. Effects of saline and LHRH antagonist injection into the MPO on the LH surge

\begin{tabular}{lcccccccccc}
\hline \multirow{2}{*}{ Treatment } & \multirow{2}{*}{ Number of rats } & \multicolumn{10}{c}{ Time $(\mathrm{h})$} \\
\cline { 3 - 11 } & & 1200 & 1300 & 1400 & 1500 & 1600 & 1700 & 1800 & 1900 & 2000 \\
\hline Saline & 6 & $0.7 \pm 0.1$ & $1.1 \pm 0.2$ & $11.3 \pm 5.3$ & $32.8 \pm 7.1$ & $30.5 \pm 4.8$ & $17.6 \pm 4.4$ & $7.5 \pm 1.4$ & $4.2 \pm 4.2$ & $2.5 \pm 0.2$ \\
LHRH-A 100 ng & 5 & $0.8 \pm 0.1$ & $1.1 \pm 0.3$ & $4.2 \pm 3.1$ & $11.8 \pm 5.2^{*}$ & $23.1 \pm 5.6$ & $25.4 \pm 2.7$ & $15.3 \pm 1.1^{*}$ & $7.9 \pm 0.8^{*}$ & $4.4 \pm 0.3^{*}$ \\
\hline
\end{tabular}

Values are expressed as the mean \pm SEM. ${ }^{*} P<0.05$ vs. saline control. 
Table 3. Effects of saline or LHRH injection into the MPO on the LH surge

\begin{tabular}{lcccccccccc}
\hline Treatment & \multicolumn{1}{c}{ Number of rats } & \multicolumn{10}{c}{ Time (h) } \\
\cline { 2 - 10 } & & 1200 & 1300 & 1400 & 1500 & 1600 & 1700 & 1800 & 1900 & 2000 \\
\hline Saline & 7 & $0.9 \pm 0.1$ & $0.9 \pm 0.1$ & $1.0 \pm 0.1$ & $2.2 \pm 0.6$ & $16.3 \pm 4.2$ & $27.9 \pm 5.0$ & $25.7 \pm 3.2$ & $14.5 \pm 1.2$ & $7.9 \pm 0.4$ \\
LHRH 10 ng & 7 & $0.8 \pm 0.1$ & $0.7 \pm 0.1$ & $1.2 \pm 0.1$ & $10.0 \pm 3.2^{*}$ & $36.0 \pm 3.3^{*}$ & $29.6 \pm 3.0$ & $16.5 \pm 1.0$ & $10.7 \pm 0.9^{*}$ & $5.7 \pm 0.7^{*}$ \\
\hline
\end{tabular}

Values are expressed as mean $\pm \mathrm{SEM}$. ${ }^{\star} P<0.05$ vs. saline control.

of the pulsatile LH secretion in OVX rats, but the same treatment had certain effects in proestrous rats. The results provide additional information indicating that the ultra-short positive feedback action depends on the presence of gonadal steroids on the day of proestrus.

The results in OVX rats are quite different from those of other researchers who have shown decreases in LH secretion following intracerebroventricular injections of LHRH in OVX rats $[1,2,3]$ and ewes [4]. The difference in the results is probably related to the difference in the injection site. Such differential effects of neuropeptides on $\mathrm{LH}$ secretion depending upon the site of microinjection in the brain were also found in the case of neurotensin; the injection of neurotensin into the MPO did not affect pulsatile LH secretion in OVX rats [13] but that into the third ventricle inhibited the LH secretion [14]. Intracerebroventricularly injected LHRH probably acts on hypothalamic areas other than the MPO; for example on the mediobasal hypothalamus $[5,6]$, to inhibit its own secretion in OVX rats. Their results on the inhibition by intracerebroventricular LHRH injection are not inconsistent with our results showing no effect of LHRH injection into the MPO of OVX rats.

It is further suggested that the effect of injections in proestrous rats is not due to the peptide leaked to the pituitary, since the same treatment as that which influenced the LH secretion in proestrous rats had no effect in OVX rats.

The LHRH antagonist we used in the present study is a competitive antagonist that reduces the amount of LH normally secreted in response to LHRH by inhibiting the binding of LHRH to the pituitary cells [8]. It is therefore assumed that the action of LHRH, which was secreted within the MPO like a neurotransmitter or neuromodulator, was inhibited by treatment with antagonist, leading to a delay in the timing of the LH surge. We suppose that the endogenous LHRH secreted in the MPO contributes to the explosive activation of a large number of LHRH neurons, resulting in the surge of LH secretion.

\section{Acknowledgments}

We wish to thank the NIDDK for providing radioimmunoassay materials, and Dr. K. Wakabayashi, Gunma University (Maebashi, Japan), for his help with the radioimmunoassay. We also thank Dr. Philip J. Brooks, NIAAA/NIH (Rockville, USA) for critical reading of the manuscript.

\section{References}

1. Sarkar DK (1987) In vivo secretion of LHRH in ovariectomized rats is regulated by a possible autofeedback mechanism. Neuroendocrinology 45: 510-513.

2. Bedran de Castro JC, Khorram O, McCann SM (1985) Possible negative ultrashort loop feedback of luteinizing hormone releasing hormone (LHRH) in the ovariectomized rat. Proc Soc Exp Biol Med 179: 132-135.

3. DePaolo LV, King RA, Carrillo AJ (1987) In vitro and in vivo examination of an autoregulatory mechanism for luteinizing hormone-releasing hor- mone. Endocrinology 120: 272-279.

4. Naylor AM, Porter DWF, Lincoln DW (1989) Inhibitory effect of central LHRH on LH secretion in the ovariectomized ewe. Neuroendocrinology 49: 531-536.

5. Zanisi M, Messi E, Motta M, Martini L (1987) Ultrashort feedback control of luteinizing hormonereleasing hormone secretion in vitro. Endocrinology 121: 2199-2204.

6. Valença MM, Johnston CA, Ching M, Negro-Vilar A (1987) Evidence for a negative ultrashort loop feedback mechanism operating on the luteinizing 
hormone-releasing hormone neuronal system. Endocrinology 121: 2256-2259.

7. Hiruma H, Funabashi T, Kimura F (1989) LHRH injected into the medial preoptic area potentiates LH secretion in ovariectomized estrogen-primed and proestrous rats. Neuroendocrinology 50: 421426.

8. Rivier JE, Vale WW (1978) [D-pGlu ${ }^{1}, \mathrm{D}-\mathrm{Phe}^{2}, \mathrm{D}-$ $\operatorname{Trp}^{3,6}$ ] - LRF. A potent luteinizing hormone releasing factor antagonist in vitro and inhibitor of ovulation in the rat. Life Sci 23: 869-876.

9. Sarkar DK, Chiappa SA, Fink G, Sherwood NM (1976) Gonadotropin-releasing hormone surge in pro-oestrous rats. Nature 264: 461-463.

10. Park OK, Ramirez VD (1989) Spontaneous changes in LHRH release during the rat estrous cycle, as measured with repetitive push-pull perfusion of the pituitary gland in the same female rats. Neu- roendocrinology 50: 66-72.

11. Funabashi T, Kato A, Kimura F (1990) Naloxone affects the luteinizing hormone secretory pattern in the short- and long-term ovariectomized rat. Neuroendocrinology 52: 35-41.

12. Gallo RV (1981) Pulsatile LH release during the ovulatory LH surge on proestrus in the rat. Biol Reprod 24: 100-104.

13. Akema T, Preputpittaya C, Kimura F (1987) Effects of preoptic microinjeciton of neurotensin on luteinizing hormone secretion in unanesthetized ovariectomized rats with or without estrogen priming. Neuroendocrinology 46: 345-349.

14. Vijayan E, McCann SM (1980) In vivo and in vitro effects of substance $P$ and neurotensin on gonadotropin and prolactin release. Endocrinology 105: 6468. 